\title{
Origen del embarazo temprano en adolescentes mexicanas: contextos, significados y experiencias
}

\section{Origin of early pregnancy in Mexican adolescents: contexts, meanings and experiences}

\author{
José Salvador Sapién-López y Estefany Berenice Manjarrez-Hernández \\ Facultad de Estudios Superiores Iztacala de la Universidad Nacional Autónoma \\ de México Universidad Nacional Autónoma de México, México \\ Escuela de Enfermería del Instituto Nacional de Enfermedades Respiratorias
}

\section{Resumen}

Se han abordado las causas y consecuencias del embarazo adolescente, pero no su origen psicosocial. Pretendemos analizar su génesis paulatina. La investigación fue cualitativa. Siete mujeres de la Ciudad de México, y zona conurbada, que vivieron un embarazo a sus 14 o 15 años de edad, fueron entrevistadas. Se realizaron categorías para clasificar la información. El embarazo fue precedido por: noviazgos, de contacto corporal cada vez más íntimo; menarquia; permiso paterno; renuencia masculina y connivencia femenina a usar condón post debut sexual; métodos anticonceptivos inaccesibles por minoría de edad; débil resistencia a la incitación masculina respecto del cortejo, contacto erótico y coito; relación bidireccional unión conyugal-embarazo; y secuencia (sexo no protegido-fecundación inadvertida-síntomas de embarazo-incertidumbre del embarazo-pruebas de embarazo confiables-certitud del embarazo-descarte del aborto). El embarazo temprano ocurrió tras una secuencia de hechos dentro de la trayectoria de vida, bajo normas de género inequitativas sobre sexualidad, reproducción y unión conyugal.

Palabras clave: Embarazo, adolescentes mexicanas, contextos, significados, experiencias.

\section{Abstract}

The causes and consequences of teenage pregnancy have been addressed, but not its psycosocial origin. We intend to analyze its gradual genesis. The research was qualitative. Seven women from Mexico City, and the conurbation area, who experienced a pregnancy when they were 14 or 15 years old, were interviewed. Categories were made to classify the information. The pregnancy was preceded by: progressively increased intimate body contact courtships; menarche; parental authorization; male reluctance and female connivance to use condom after sexual debut; inaccessible contraceptive methods due to being a minor; weak resistance to male incitement during courtship, erotic contact, and intercourse; bidirectional pregnancy-marriage relationship; and a sequence (unprotected sex - inadverted fertilization - pregnancy symptoms - pregnancy uncertainty - reliable pregnancy tests - pregnancy certittude - abortion rejection). Early pregnancy occurred after a sequence of events within the life trajectory, under unequal gender norms on sexuality, reproduction, and conjugal union.

Keywords: Pregnancy, Mexican adolescents, contexts, meanings, experiences. 


\section{INTRODUCCIÓN}

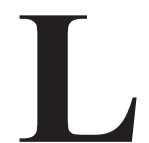

a definición común de embarazo, recuperada por Mothiba y Maputle (2012), refiere el estado en que se desarrolla un feto en el útero de una mujer fértil, durante el periodo que ordinariamente inicia con la concepción y termina con el nacimiento. Puesto que la adolescencia suele quedar delimitada entre los 15 y 19 (Stern, 1997), o entre los 13 y 19 años (Mothiba y Maputle, 2012), el embarazo adolescente sería el período de gestación de una mujer entre 13 y 19 años de edad. Mas habría que contemplar casos de niñas embarazadas apenas a sus 10 años (Habitu, Yalew y Bisetegn, 2018). Si bien lo referido por concepción y embarazo es producto biológico de la unión sexual entre dos individuos fértiles de diferente sexo, ocurre dentro de un marco social y cultural determinado. Por ello, las concepciones de Gagnon (1980), Cazés (2000), Bourdieu (2000), Lagarde (1997) y Rubin (1986) son importantes para la comprensión del origen psicosocial del embarazo, en particular del embarazo temprano.

Lo que Gagnon definió como guiones del comportamiento sexual es valioso para comprender los orígenes de la concepción y el embarazo, ya que estos guiones establecen en cada sociedad con quién, cuándo, dónde, cómo, para qué y por qué involucrarse en la actividad sexual, sea fértil o infértil. Acordemente, nuestra sociedad posee sus propios guiones sexuales, que orientan la conducta de sus miembros. Para el pensamiento de Cazés, más radical que el de Gagnon, nuestra sociedad patriarcal y sexista (machista, misógina, homofóbica), más bien mandata conductas diferentes, desiguales e inequitativas para hombres y mujeres, privilegiando lo masculino. El desiderátum, o conjunto de deseos e imperativos sociales, específicos para cada sexo, se impone a los individuos mediante coerción; otorga poder a los varones sobre las mujeres en la vida social, especialmente en temas de sexualidad y reproducción. Para Bourdieu la dominación masculina se estructura de forma simbólica según una cosmovisión histórica, que hoy contrapone lo masculino y lo femenino, considerando incuestionable la inferioridad social de las mujeres, como si fuese natural. Es así, como planteó Lagarde, que las mujeres de la sociedad mexicana, patriarcal y sexista, viven subyugadas bajo la hegemonía masculina y confinadas en algún cautiverio, como madresposas, monjas, presas, putas y locas, cuyos cercos arquitectónicos y simbólicos, conducta sexual y vínculos con las instituciones familiar, clerical, legal, sanitaria y conyugal son específicos, pero congruentes entre sí. Las representaciones y prácticas en nuestra sociedad respecto de la concepción y el embarazo, las cuales son expresiones 
de la incidencia de estos cautiverios e instituciones, serían productos de la dominación masculina y la sumisión femenina. Por su parte, según Rubin, el sistema patriarcal de parentesco y de sexo/género de una comunidad particular, dígase la nuestra, determina qué mujeres pueden ser objeto de actividades sexuales y transacciones o acuerdos conyugales.

Aunque faltan estudios en México que analicen los guiones sexuales, o el desiderátum, o los cautiverios vigentes en nuestra sociedad, o su sistema de parentesco y de sexo/género, que permitan conceptualizar el origen del embarazo, si debiera explicitarse un canon hegemónico existente hoy sobre las relaciones sexuales y la edad de las mujeres, es éste: no con parientes cercanos ni durante la infancia, pubertad o adolescencia temprana. Efectivamente, esta regla contrasta con las de sociedades donde niñas incluso de siete años son tomadas en matrimonio (Birech, 2013). La oposición de la familia contra el vínculo sexual de sus miembros femeninos y masculinos de corta edad es más férrea si por éste se produce lo que ha sido denominado y problematizado como embarazo adolescente. Pero, aunque este embarazo sea desacreditado en sociedades como la nuestra, ocurre en alguna magnitud. De hecho, Welti reportó en el 2000 que en los 20 años precedentes a 1997 la fecundidad decayó en México casi 50 por ciento, mientras que en las mujeres de 15 a 19 años disminuyó sólo 39 por ciento, por lo que su participación en la fertilidad general incrementó. Posteriormente el mismo autor (Welti, 2012) verificó esta tendencia decreciente de la fecundidad de las adolescentes. Datos más recientes sobre el contexto mexicano, proporcionados por el Instituto Nacional de Estadística y Geografía, INEGI (2019), indican que, si bien el porcentaje de nacimientos registrados de madres menores de 20 años había tendido a incrementar entre 1994 y 2013, llegando a 19.4 por ciento, a partir de este último año comenzó a disminuir, hasta tocar un valor de 17 por ciento en 2019. Por su parte, Arceo y Campos (2014) mostraron datos del Banco Mundial, según los cuales en México 69 de cada 1,000 adolescentes de 15 a 19 años tienen hijos, en tanto que en Estados Unidos lo hacen 36 por 1,000. En comparación con países latinoamericanos, las tasas de maternidad adolescente en México están entre las de Brasil (76 por cada 1,000 mujeres) y las de Argentina y Chile (56 y 57 por cada 1,000 , respectivamente).

Se ha investigado el embarazo adolescente en distintas latitudes. Hay estudios cuantitativos en Estados Unidos que subrayan sus causas. Anda, Chapman, Felitti, Edwards, Williamson, Croft, Giles y Wayne (2002), en California, hallaron que es más probable que hombres con más experiencias adversas en su niñez (abuso sexual o algún crimen) embaracen a una 
mujer adolescente, en contraste con quienes tuvieron menos experiencias de ese tipo. Kohler, Manhart y Lafferty (2008), en Seattle, mostraron que los adolescentes que recibieron educación sexual comprehensiva tuvieron menor riesgo de embarazo que los que recibieron una educación orientada a la abstinencia sexual o carecieron de educación sexual explícita. Duberstein Lindberg, Maddow-Zimet y Boonstra (2016), en Nueva York, hallaron que la declinación de la educación sexual formal y de las tasas de comunicación con los padres sobre esa materia privan a los adolescentes de instrucción sexual valiosa, más en zonas no metropolitanas. Santelli, Kantor, Grilo, Speizer, Lindberg, Heitel, Schalet, Lyon, Mason-Jones, McGovern, Craig, Rogers y Ott (2017) revelaron que la educación y las políticas sanitarias de ese país, que poseen un trasfondo religioso y proclaman la abstinencia sexual hasta el matrimonio, fracasan en retardar la iniciación sexual y prevenir las infecciones de transmisión sexual y el embarazo adolescente.

Estudios cuantitativos en África también han analizado algunos factores del embarazo adolescente. Nyakubega (2009), en Tanga, Tanzania, sostuvo que el bajo nivel socioeconómico es su principal determinante. Mothiba y Maputle (2012), en Limpopo, Sudáfrica, identificaron varios factores que lo aumentan: falta de conocimientos sobre sexo y cómo usar anticonceptivos; barreras diversas para acceder a los anticonceptivos; presión de los pares; coerción sexual; baja autoestima; bajas expectativas educativas; pobreza; desintegración familiar; y abundancia de mensajes sobre sexo en los medios de comunicación. Gyan (2013), en Accra, Ghana, planteó que sus causas son la mala crianza de los hijos, la pobreza y la influencia de los pares. El estudio cualitativo de Gyesaw y Ankomah (2013), también en Accra, mencionó los siguientes factores de la actividad sexual temprana y el embarazo resultante: relaciones sexuales transaccionales para satisfacer necesidades básicas; violencia sexual y explotación; y búsqueda del respeto de las personas en la sociedad. Yadufashije, Sangano y Samuel (2017), en su artículo de revisión, identificaron dos factores relevantes del embarazo adolescente en países africanos: (i) las creencias tradicionales de los padres sobre reproducción y sexualidad y (ii) la pobreza.

En Asia también se ha abordado el tema. Pogoy, Verzosa, Coming y Agustino (2014), en su estudio cualitativo realizado en Filipinas, reportaron que la curiosidad, los problemas financieros y familiares y las emociones fuera de control propician el embarazo en mujeres adolescentes, sean de alto (promedio de 85 por ciento y mayor) o de bajo nivel (promedio de 84 por ciento y menor) escolar. La revisión de Panting, Abdullah, Roslan e 
Ismail (2019), en Sarawak, Malasia, dilucidó sus factores de riesgo: migración rural-urbana, relaciones familiares disfuncionales, fallas en el derecho consuetudinario matrimonial, abuso de alcohol y otras drogas, escaso conocimiento sobre la salud sexual y reproductiva, y uso de pornografía. Welti (2000) afirmó que el nivel de educación de una mujer fue el factor más asociado con la probabilidad de dar a luz en la adolescencia. Otros factores importantes son el tamaño de la localidad de residencia y la condición étnica (Welti, 2012).

Las consecuencias del embarazo adolescente, por las que es visto como problema, son: reducción de las horas de estudio y de la concentración durante éste (Gyan, 2013), menor asistencia a la escuela, pérdida de 1 a 1.2 años en años de educación (Arceo-Gomez y Campos-Vazquez, 2014), baja posibilidad de culminar los estudios (Pogoy, Verzosa, Coming y Agustino, 2014), abandono de la escuela (Gyan, 2013; Yadufashije, Sangano y Samuel (2017), incluso sin ver posibilidad de regresar a ella (97 por ciento) Gyan, 2013), menor ingreso económico per cápita en el hogar y mayor tasa matrimonial (Arceo-Gomez y Campos-Vazquez, 2014).

Puesto que pretendemos ahondar la comprensión del origen psicosocial del embarazo temprano, más que conocer sus causas y consecuencias, resulta valioso el trabajo cualitativo, holístico, de Aparicio, Vanidestine, Zhou y Pecukonis (2016) en Mayland, Estados Unidos. Mediante entrevistas semi-estructuradas con adultos jóvenes latinos (incluidos de México), la teoría fundamentada y un enfoque de género, los autores discernieron siete conceptos (y hallazgos) sobre embarazo adolescente: (i) expectativas sexuales (para ellos el sexo es cuestión de hombría, pero ellas deben abstenerse hasta el matrimonio); (ii) aprendizajes sobre sexo y embarazo (lo enseñado, como no tener sexo o tener que abandonar el hogar por embarazo, ocurre en la familia, la escuela y la comunidad); (iii) clase social (el embarazo adolescente se atribuye al nivel económico bajo); (iv) compañeros (la mayor influencia es ver que los conocidos son sexualmente activos, cursan embarazos o tienen hijos); (v) patrones de comunicación familiar sobre sexo y embarazo (insuficiente abordaje del sexo y el embarazo, con menos participación del padre que de la madre); (vi) religión (supuesta pérdida de la pureza e inculpación centrada en la joven por tener sexo; y desaprobación de la contracepción y el aborto); y (vii) factores protectores (respeto, reputación, miedo de decepcionar a la familia; planes a futuro; expectativas de primera generación; y supervisión).

Otro estudio cualitativo apreciable es de Kiluvia (2011), en Mgama, Tanzania, quien colectó las nociones y discursos dominantes sobre género, 
sexualidad y reproducción que distinguen a los sexos y marcan un desequilibrio de poder entre ambos: (i) Ser hombre implica poder preñar, tomar decisiones independientes, ser responsable como jefe de hogar y sostén de la familia, ser confiado, atrevido, convertirse en líder y ser respetado por niños y mujeres. (ii) Ser mujer se asocia con habilidades reproductivas, domésticas y de socializar a los hijos. Contrastes que halló: los adolescentes, a diferencia de los hombres adultos y de las muchachas, son menos responsables; las adolescentes son más ingenuas, emocionales, débiles e irracionales que los muchachos; se espera más obediencia de ellas que de ellos hacia sus padres. En materia sexual encontró posturas opuestas: los hombres son más libres que las mujeres de iniciar conversaciones y relaciones sexuales; la sexualidad de las y los adolescentes es más restringida que la de los hombres adultos; se espera abstinencia sexual de los jóvenes hasta el matrimonio, más en las mujeres; a diferencia de las chicas, los muchachos son admirados por tener sexo; se responsabiliza a las adolescentes de que los hombres usen condón porque se cree que ellos tienen sensaciones sexuales más fuertes; los motivos para tener sexo difieren (las adolescentes por dificultades económicas, ellos por deseo); y las adolescentes con carencias económicas son atrapadas sexualmente porque no pueden rechazar los regalos o el dinero que les ofrecen. Estas nociones y discursos dan forma a percepciones y comportamientos de las y los adolescentes y los hombres de más edad, estando de por medio la agencia (capacidad individual de decidir y actuar); naturalizan la sexualidad de los hombres y catalogan sus conductas sexuales como inevitables, mientras suprimen la de las mujeres.

Sin embargo, falta analizar de forma holística, pero también secuencial, el embarazo temprano, en el sentido de recuperar contextual y biográficamente los sucesos, actividades cotidianas, experiencias, significaciones y aprendizajes de las adolescentes que, en sus ámbitos patriarcales, las fueron conduciendo con gradualidad al embarazo, con la mediación de su agencia y la de otros. Por ello, el objetivo fue analizar, desde un enfoque de género, el origen psicosocial paulatino del embarazo temprano, según las perspectivas, experiencias y significados de mujeres que lo vivieron a sus 14 o 15 años de edad, período poco explorado.

\section{Metodología}

Este estudio, de tipo cualitativo (Taylor y Bogdan, 1996; Maputle; 2006; Álvarez-Gayou, 2007; Hernández, Fernández y Baptista, 2010) y contenido autobiográfico (Taylor y Bogdan, 1996), siguió un método fenomenológico al levantar la información (Maputle, 2006; Hernández, Fernández 
y Baptista, 2010). La técnica empleada fue la entrevista semiestructurada mencionada por Vela (2004), y O'Keeffe, Buytaert, Mijic, Brozović y Sinha (2016), la cual trata acerca de una temática y ayuda a guiar la conversación y que emerjan tópicos relacionados. La entrevista arroja datos cualitativos y cuantitativos, información sobre prácticas y percepciones (O'Keeffe, Buytaert, Mijic, Brozović y Sinha, 2016) e información holística acerca de las experiencias individuales (Maputle, 2006).

\section{Participantes}

Se contó con la participación de siete mujeres. El criterio de inclusión fue que hubieran vivido un embarazo a los 15 años de edad o antes. Dos participantes vivían en la ciudad de México y cinco en la zona conurbada del Estado de México. Sus edades fueron comprehendidas entre 15 y 25 años $($ Media $=21.14)$. Sus estudios escolares fueron de secundaria inconclusa a bachillerato incompleto. Eran casadas (dos), vivían en unión libre (UL) (tres) o estaban separadas (dos). Todas las participantes eran católicas. Su edad promedio al embarazo fue de 14.71 años. Su trabajo común fue hogareño. Su número de hijos fue de 1 a 5 . Quienes las embarazaron por lo general eran mayores que ellas; sus actividades laborales eran manuales y no requerían niveles escolares avanzados (ver Tabla 1).

\section{Negociación}

Las participantes fueron contactadas mediante la técnica de bola de nieve, esto es, personas conocidas por la investigadora y algunas participantes que ya habían aceptado la invitación a formar parte del estudio fueron un apoyo valioso para que otras aceptaran ingresar al mismo. El primer o único día de entrevista las participantes firmaron el documento de consentimiento informado, que aseguraba los principios éticos de la investigación: no maleficencia, confidencialidad, anonimato y autonomía.

\section{Instrumento}

Se utilizó el documento de consentimiento informado mencionado y un guión de entrevista que incluyó los datos generales de las participantes y sus experiencias en torno a su primer o único embarazo. 


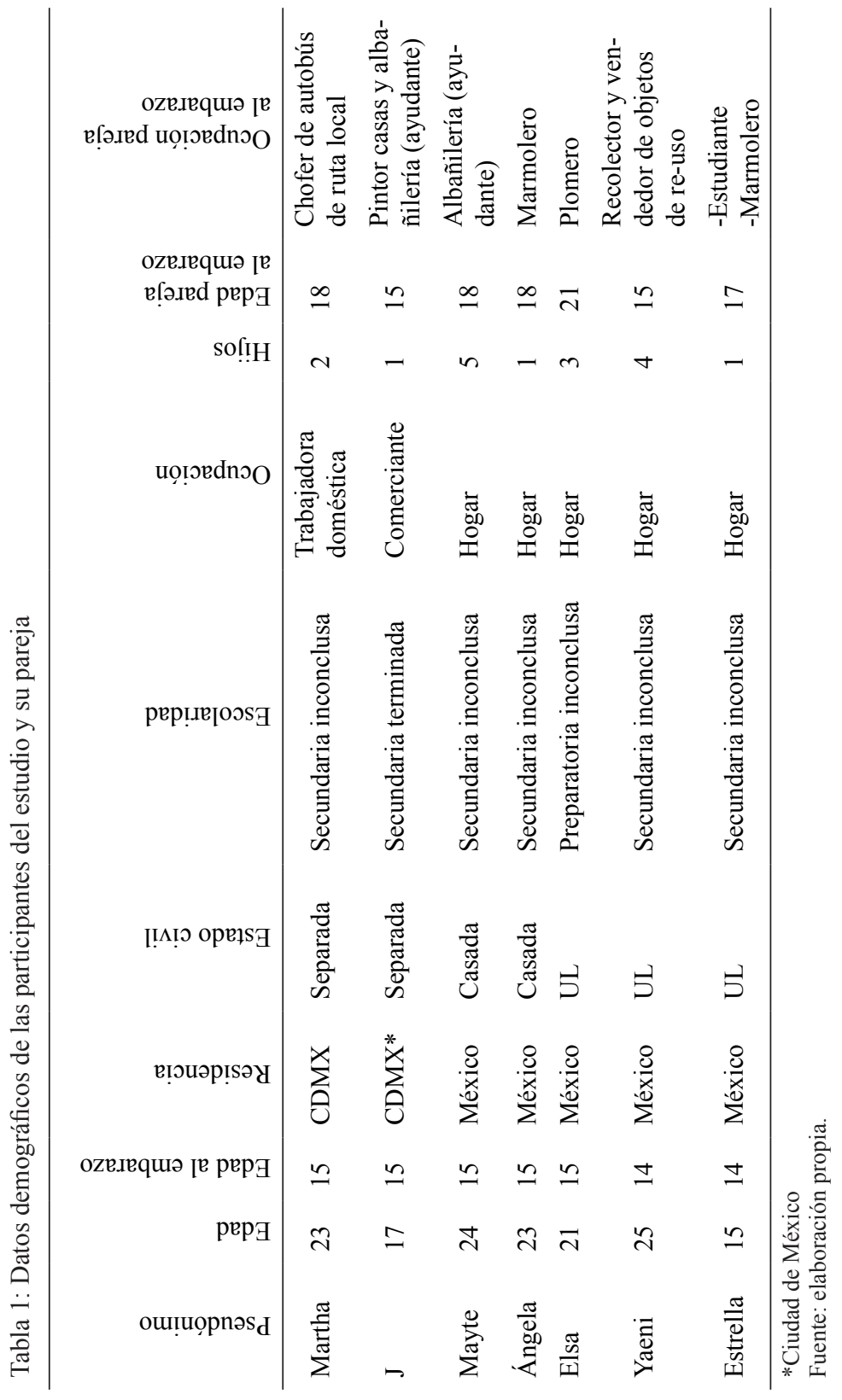




\section{Procedimiento de entrevista}

Las participantes fueron entrevistadas por la investigadora. Cada entrevista se realizó individualmente vis a vis, con base en la guía temática. La entrevistadora asumió una actitud conversacional, empleando una terminología cotidiana, evitando términos técnicos. Se llevaron a cabo en casa de las participantes o en lugares cercanos a ésta, por el número y durante el tiempo necesario (ver Tabla 2) para cubrir los temas de interés. Las entrevistas fueron audio grabadas con su autorización. En caso de que alguna participante se conmoviera emocionalmente, la entrevista y la grabación se pausaron y se le brindó consuelo, omitiendo por segundos o minutos el suceso conmovedor recordado.

Tabla 2: Número, lugar y duración de las sesiones de entrevista a cada participante

\begin{tabular}{lcll}
\hline Pseudónimo & Número de sesiones & \multicolumn{1}{c}{ Lugar } & Duración \\
\hline Martha & 1 & Su casa & 66 minutos \\
$\mathrm{J}$ & 1 & Paletería y parque deportivo & 62 minutos \\
Mayte & 1 & Frente a su casa & 44 minutos \\
Ángela & 2 & -Casa de su tía & -30 minutos \\
Elsa & 2 & -Casa de su suegro & -90 minutos \\
Yaeni & 1 & Su casa & -75 minutos \\
Estrella & 2 & Su casa & -35 minutos \\
& & Su casa & 51 minutos \\
\end{tabular}

Fuente: elaboración propia.

\section{Notas de campo}

Unas horas después de cada entrevista se elaboró una nota de campo con comentarios sobre sucesos destacados antes, durante o después de ésta: cambio del lugar de entrevista, presencia, actitud o paso de personas, posible percance en la grabación, descripción del hogar, cuidados y vigilancia maternal, cortesías de la anfitriona o de la entrevistadora.

\section{Transcripción de entrevistas}

Cada sesión de entrevista fue transcrita. En la transcripción se buscó reiteradamente una correspondencia literal entre el discurso oral, de base, y el texto escrito producido. 


\section{Codificación y análisis de los datos}

Se construyeron categorías de contenido a posteriori con base en la revisión de las transcripciones de las entrevistas y la contemplación del propósito del estudio. Estas categorías se usaron como rubros para clasificar lógica y cronológicamente la información, donde se ubicaron fragmentos de los relatos de las participantes para testimoniar sus acciones y experiencias en torno a su embarazo. Los hallazgos se interpretaron desde una perspectiva teórica de género.

\section{Resultados}

A continuación se describen sucesos vividos por las participantes y que fueron precursores, desencadenantes o concomitantes de su implicación en un embarazo temprano. Estas experiencias consecutivas, bajo distintos rubros, ubican al embarazo como momento significativo de un proceso psicosocial longitudinal que incluye lo emocional, lo sexual y lo reproductivo.

\section{Implicación en noviazgos desde la niñez o la pubertad}

El noviazgo es una práctica social-afectiva-erótica-sexual que mujeres y hombres conocen desde temprano. Las participantes, con excepción de Ángela, tuvieron su primer novio en la niñez o la pubertad. Los noviazgos quedaron pactados en cuanto ellas dieron el "sí" a quienes las cortejaban. Los noviazgos, más breves y lábiles cuanto más tempranos, se disolvieron con el desinterés declarado o tácito de ella o él. Los ambientes más propicios del noviazgo fueron la escuela, el vecindario y, más tarde, las fiestas. Los compañeros de escuela, de grupo, de grados más avanzados y los vecinos más atrevidos fueron los novios más comunes.

Ellas vivieron sentimientos de amor intenso en sus noviazgos postreros, pero también aburrimiento, incomodidad o indiferencia. La ruptura de noviazgos a veces causó alivio, tristeza, desilusión, o nada importante. El abandono o una desilusión en el noviazgo dejaron huella: una frustración, un triste recuerdo. Un sobre entendido respecto del noviazgo es la exclusividad de pareja, que no siempre se cumple. El cortejo, pedir permiso a los padres, el liderazgo, los gastos, recogerlas y regresarlas a casa, las visitas, los obsequios y los paseos fueron funciones galantes adjudicadas los hombres, que las asumieron.

Desde el nivel preescolar se observa predisposición al noviazgo o a oponérsele: 
Yaeni: Decían que yo era su novia, pero no era su novia, fue en el kínder (...). Me robaron un beso y hasta me puse a chillar y le dije a la maestra. Ese niño decía que yo era su novia y su mamá también decía que yo iba a ser su novia cuando yo creciera.

Ejemplo de un noviazgo infantil en la escuela primaria también implicó a Yaeni:

Fui muy noviera desde la primaria, creo que en tercer año fue mi primer novio, todo lo normal desde chiquitos, cuando somos novios, que agarrados de la mano, que me invitaba la paleta, que pulseritas.

Ella misma se involucró después en un noviazgo, evadiendo la prohibición de su padre:

En sexto, yo tendría como 10, 11 años, él tendría ya como 15 (...). Mi papá decía "No, ¿cómo crees?, si es mayor que tú", y yo "Pero no me importa (...) a mí me gusta y yo lo quiero", entonces anduve a escondidas con él, con él duré dos años (...). Él fue mi primer amor (...). Fue con el que duré más, y ya se terminó, triste.

Un noviazgo de implicación emocional en la Secundaria fue el de Estrella:

En primero íbamos en el mismo salón (...). Estábamos juntos en el descanso, estábamos juntos todo el día (...). En segundo me cambiaron de salón (...) por (mal) comportamiento (...). Me cambiaron un día antes de cumplir el año (de novios) (...). Sentí más feo porque un día antes nos habíamos peleado (...) por Facebook (...). Sentí muy feo porque dejamos de hablarnos.

\section{Circunstancias en que conocieron a la pareja}

Fiestas (Mayte, Elsa, Ángela, Yaeni), ratos de diversión en cancha de futbol (Martha), comunicación por Facebook $(\mathrm{J})$ propiciaron los primeros encuentros de las chicas con quienes las embarazarían. Los conocieron por iniciativa propia (Martha y J) o por mediación de la hermana (Ángela), una prima (Elsa), la novia de él y amiga propia (Mayte) o siendo cortejada tras un encuentro imprevisto (Yaeni). Ejemplos:

Martha: Nos gusta mucho el futbol y nos íbamos aquí a la cancha (...) a jugar (...), ahí lo conocí (...). De chamaquitas éramos bien loquitas (ríe, se ruboriza) (...), (él) pasaba y (...) yo le hablaba (llamando su atención). 
J: En el Face(book) (...) le envíe solicitud (...). Yo le empezaba a hablar y una vez dijimos que nos íbamos a hablar en persona (...). Me fui de pinta (no entrar a la escuela) con una de mis amigas y lo vi en el sitio (de taxis).

Elsa: Me sacó a bailar y ya de ahí (mi prima) le dio mi número de teléfono (...). Él me empezó a hablar (...). La fiesta fue más que nada familiar, (por) primeras comuniones.

\section{Dando el "sí": inicio del noviazgo}

Después del cortejo, coqueteo, declaración de amor/interés y petición de noviazgo del pretendiente, ellas dieron el "sí". La petición fue directa (Mayte, Martha, Yaeni, Estrella, Ángela), por teléfono (Elsa), o en Facebook (J). La aceptación de ser novia sucedió cuando no se tenía otro noviazgo (Mayte, Ángela, Elsa, J, Martha), después terminar un noviazgo a petición del nuevo aspirante (Yaeni), o teniendo novio, estando incluso enamorada de él (Estrella).

El noviazgo de Mayte fue con el ex novio de una amiga, tras el segundo intento de él; el de Elsa fue con el hermano de un tío a la primera petición mediante mensaje telefónico; el de Yaeni fue con quien le pidió que dejara a su novio actual, después de meditar eso, a la siguiente petición; el de Estrella fue doble ya que despechada por su novio aceptó ser novia también de otro después de numerosas imploraciones de éste; el de Martha fue con un compañero de juegos obstinado, a quien le dio el sí por incontables súplicas. Véanse dos ejemplos del proceso de cortejo, declaración del pretendiente y aceptación de la chica: (1) con interés de ella (Yaeni) y (2) con desánimo y resistencia (Martha).

(1) Yaeni: A la secundaria yo iba caminando y tenía que cruzar un parque (...). Me decía que "iQué guapa!", que "iQué bonitos ojos!” (...). Cuando estaba yo adentro de casa de mi abuela escuché que me gritaron (...) "Te hablan, que te quieren conocer" y yo "No, no quiero" (...). Me preguntó "¿Que si te gusta el muchacho de acá afuera?" y yo "Ah. Se me hace guapo", "TTe habla!", y yo "No, no quiero", me daba pena, y que (mi prima) me jala de la mano y me saca (...). Me lo presentó (...). Él me dijo “¿Te dejan platicar acá afuera de mi casa?” porque a él no lo dejaban salir mucho (...). Le dije “iSí, vamos!” y me puse a platicar. El abusivo me quería besar (...), me hice para atrás (...) y me iba a caer de la jardinera (...), fue cuando me dijo que si quería ser su novia y le dije que no porque yo ya tenía novio, y él me dijo “iDéjalo!” y le dije “¡No! ¿Cómo crees?”. Lo pensé como por tres días y sí lo dejé y ya después él me dijo que si quería ser su novia y así pasó todo. 
(2) Martha: Él decía que anduviéramos (...). A mí él no me gustaba (...). Me dijo “¡Ya, ándale! ¡Vamos a andar!” (...). Me convenció y empecé a andar con él (...), pero a fuerza (...), al principio yo no quería. Después dije "Bueno, le voy a dar una oportunidad. sí".

A partir del "Sí”, y la formalización del noviazgo, fueron admisibles los arrumacos y el magreo propios de este tipo de relación de pareja.

\section{Autorización del noviazgo de la adolescente}

Cuando la relación de noviazgo ya existía a escondidas de los padres de la novia, el varón les pidió y obtuvo su permiso de andar públicamente con ella, para mayor seriedad: salir a caminar, acompañarla entre su casa y la escuela, ir a fiestas, sacarla a pasear, visitarla en casa, acompañarla en eventos familiares. El caso de Elsa es un ejemplo:

Ya teníamos como cuatro meses de novios y él pasó a hablar con mis papás que quería ya algo más serio (...). Yo apenas tenía 12 años, iba en primero de secundaria (...). Una vez que ya sabían quién era mi novio ya me dejaban salir con él (...). Como era hermano de mi tío X: (...) "Está bien” (...) “¡Respétala!” (...), no fue el papá tan enojón (...). Mi mamá (...) me dijo nada más que me cuidara (...), que no fuera a tener relaciones (...). Él venía por mí y nos daban, por mucho, dos horas de salir (...) Íbamos a comer y nos regresábamos, o luego se venía aquí a la casa (...). Platicábamos o veíamos películas.

\section{Fin de la infancia o de la pubertad}

Dos eventos insignes de la sexualidad que marcan la entrada de las mujeres a otra etapa son la menarquia y el quinceavo aniversario, ambos de significación biológica, sexual y social. Ejemplifiquemos cada evento:

Estrella observó en sí misma un desarrollo físico sexual precoz:

Me desarrolle muy chiquita (...). A los diez yo ya tenía pechos (...). A los nueve empecé a reglar (...). Cuando entré a la secundaria (...) yo ya estaba bien desarrollada (...). (Mi mamá) llegó (a casa), se puso a llorar y me dijo “¡Ay! ¡Mi amor!, es que ya estás reglando ¡ya eres toda una señorita!” y yo así (gestos de extrañeza) “¿A los nueve años?”

La fiesta de XV años de Ángela fue emotiva, novelesca, con pinceladas trágico-cómicas. Así narró la invitación a chambelanes, los ensayos de baile, la preparación de la celebración, la participación familiar, peripecias y el cierre final: 
Me hicieron mi fiesta (...). Estaban las personas que yo quería y que estimaba: mis tíos, mis primos. De comer fueron carnitas y uno de mis tíos preparó piña colada para los chavos (...). Una de mis tías le ayudó a mi mamá (...). Una que otra tía la apoyaron (...). Fueron sencillos, pero me gustaron mucho (...). Yo bailé el vals con todos mis tíos (...). En vez de que se parara mi papá, fue mi mamá la que bailó (...). Mis chambelanes se movían muy bonito (...). Lo único que no me gustó (...) fue que uno de mis chambelanes $(\ldots)$, cuando pasaron las copas, sin querer dio un manotazo (...) y las copas traían fuego (...) y se cayeron y prendieron una parte de mi vestido (ríe) (...). Yo estaba llorando, ya no quería bailar (...), ya dejé de llorar y seguí bailando (...). En la última canción, fue una de El Mago de Oz, mis chambelanes traían un antifaz de la mitad de la cara, entonces yo estaba así como que buscando según mi último juguete (...). Me dieron un oso y al voltear ya estaba así mi oso convertido en mi príncipe (...). En una cargada del final me dio un beso y ya cerró (...) el vals con ese beso (...), (de) mi novio, bueno, mi esposo (...). Terminar la última pieza y darnos el abrazo fue (...) cerrar un ciclo de vernos diario a ya vernos (...) de vez en cuando.

Una condición sobreentendida para realizar esta fiesta es que la chica no se haya iniciado sexualmente todavía, según la mirada social y de la familia. Para esta participante y otras (Yaeni y Mayte), cumplir 15 años dio pauta sutil para poder hacerlo e, incluso, empezar a pensar en el nexo conyugal.

\section{Comienzo de las relaciones sexuales}

La primera relación sexual de las participantes ocurrió cuando cesaron de resistirse a las peticiones insistentes, e incluso preparativos, del novio. Ocurrió a sus 12, 14 o 15 años de edad. $J$ tuvo su primera relación sexual una vez que ella no entró a la escuela y el novio la invitó a su casa y, ya ahí, a su cuarto. Estrella aceptó iniciarse durante su primer año de secundaria en un sitio semejante. Lo hizo por ingenuidad (No logro entender cómo pasó si casi no nos hablábamos), porque se sentía desgraciada ante el abandono del novio que sí amaba y debido a su impulso sexual, en el lugar apartado y el momento excitante. Ángela tuvo su debut sexual antes de celebrarse su fiesta de XV años porque vivía un noviazgo mejor que los anteriores, sin ardides (Todos me engañaban o me dejaban por una amiga. Fue ahí donde yo me dije "Ay, sé feliz"). Elsa aceptó comenzar a tener sexo con su novio, de 20 años, justo el día que se celebraron sus XV años, evadiendo la vigilancia paterna. Fue en un momento íntimo, lejos de su casa, por su curiosidad y deseo de experimentar al despliegue de la conducta erótica, atrevida, apasionante, de él, que le evocaba experiencias 
similares en la secundaria (los compañeros que pasan y te dan nalgadas). Martha, que a sus 12 años había tenido sexo con compañeros de su edad, aceptó hacerlo con él, su tercera pareja sexual, mayor que ella, para experimentar de nuevo el sexo a sus 15 años de edad, en casa, sintiéndose madura y enamorada. Sirva el caso de Yaeni para ver una cadena de hechos que culminó en su primer acto sexual:

Es como de "Ya cumplí un mes" y te regalan flores y tú regalas algo (...). Yo ese día le iba a regalar (...) un pastel (...). Le dije "Te tengo una sorpresa de cinco letras” (...). Él lo mal interpreto, dijo que era un hotel y yo: “ ¡Un pastel!" (...). No sé si fui yo la que conté mal las letras o fue él el que entendió mal (...). Él me dedicó la canción esa de "Tengo ganas de tocarte todo tu cuerpo y hacerte el amor" (...). Yo me quedé en shock y no sé qué (se ruboriza y ríe fuerte) y ya él todo sonrojado y con pena fue cuando me dijo "Es que yo te entendí que querías ir a un hotel" y ya fue cuando él me lo propuso: "¿Y si vamos?" (...). Fuimos, pero nos corrieron porque éramos menores de edad (...), salimos del hotel todos apenados (...), sí se nos veía la cara todavía de niños (...). Pero su tío tenía un camión afuera de su casa, entonces él abría la ventana y tiene como un camarote (...). Son camioneros (...). Ahí se duermen cuando se paran, y ahí nos metimos y ahí fue (...) nuestra primera relación sexual (...). Me dijo "(...) quiero que tengas relaciones conmigo" (...), yo al principio no quería, la verdad, a mí me daba miedo, nunca había yo tenido relaciones, él fue el primer hombre (...). Me decía "No te preocupes, no te va a pasar nada" (...) y me convenció.

Yaeni y Mayté aceptaron comenzar a tener relaciones sexuales sabiendo que ellas y sus novios se iban a juntar próximamente.

\section{Actividad sexual y anticoncepción: la joven anuente}

En el debut sexual los novios de todas las participantes emplearon condón, a diferencia de su uso infrecuente en las siguientes relaciones sexuales. Esta protección anticonceptiva inconsistente no se debió en ningún caso al desconocimiento de métodos anticonceptivos sino a la oposición del novio y a la aceptación de la novia de esa indisposición. De hecho, algunas mencionaron métodos anticonceptivos que ya conocían, además del condón masculino: píldora (Martha, Yaeni y $J$ ), dispositivo intrauterino (o DIU) (Yaeni y $J$ ), inyecciones (Yaeni), implante subdérmico $(J)$ y condón femenino (Martha). Los conocieron en la escuela secundaria o en el bachillerato (Martha, Elsa, $J$ ) o por la madre (Yaeni). Actitudes del varón y la mujer anuente sobre el recurso a la anticoncepción, ante el riesgo de embarazo, fueron: indiferencia (Estrella: "cuando estás ahi no te importa"), 
negligencia (Martha: "porque ya no teníamos o ya no comprábamos y ya nada más por hacerlo") y confianza imprudente (Yaeni: "no pasa nada"). Un relato amplio:

Yaeni:

En la primera sí (usamos condón). Era casi diario (tener relaciones sexuales) (...), y no nada más en el camión sino también tenían una camioneta, en el callejón de mi casa, en una fábrica abandonada que estaba por ahí, en las escaleras de mi casa, en la casa de su tío, en todos lados donde se me presentara la oportunidad (...). Se da la ocasión de que no traes con qué (...) y dices "No pasa nada" y (...) quedé embarazada. (Usábamos) sólo el condón (...). Para ponerme otra cosa o darme pastillas necesitaban el consentimiento de mi mamá y entonces ¿cómo le vas a decir "Mamá ve conmigo al centro de salud para que me den pastillas porque voy a tener relaciones"? (...). Lo único que nos vendían eran los condones y era lo único que usaba. Mi mamá (...) me hablaba mucho de que (...) existía el DIU, que existían inyecciones (...). (pero tenía) miedo a platicarlo con mi mamá (...) “¿Qué pensará de mí?”, o quizá de que me regañara y ya no me dejara salir y no me dejara tener novio (...). Nunca lo platiqué con ella, entonces preferí la opción de usar puro condón, pero creo que no fue buena idea.

La exclusión del condón se debió también a la oposición del novio, por propósitos que la joven acabó adoptando: embarazarla para juntarse con ella (Elsa); o tener un hijo, aunque ella temía ser abandonada precisamente por el embarazo $(J)$.

\section{Escape con el novio para juntarse}

Las participantes en su adolescencia temprana se juntaron (1) por motivo de embarazo (Martha, Estrella, Elsa, Yaeni), (2) por conflictos con la madre (Ángela o Mayte) o (3) previniendo un conflicto con ella, bajo amenaza del novio $(J)$. En cada caso la chica se juntó por el interés o aceptación del novio de que ella se mudara con él. La residencia común de la pareja juntada fue en un cuarto de la casa del novio.

(1) Por embarazo. Martha, según sus afligidos recuerdos, se fue a vivir con su novio por quedar embarazada (Iba a cumplir cuatro meses cuando me fui a vivir con él). Estrella, en su razonamiento, no vio opción de permanecer en su casa al saber de su embarazo (Ese fin de semana mis papás no estaban, yo no tenía llaves de la casa, entonces no me podía ir a mi casa, y como ya estaba embarazada y ya todo ¿Qué quedaba? ;Que me quedara con él!). Elsa, sabiendo de su embarazo, fraguó con su novio, también enterado de ello, irse de casa (Si no, yo no me hubiera ido con él. Era 
así como nos íbamos a poder juntar), atendiendo el consejo de una tía ("Si, vete, si no luego van a decir que - el bebé-no es de él): Yaeni, embarazada, permaneció en casa, donde era visitada por el novio bajo supervisión de la madre, pero en una ocasión, que su novio obtuvo permiso de llevarla consigo a una boda, él se opuso a regresarla a casa, con argucias (Él ya sabía que mi mamá iba a venir por mí y me dijo “¡Vamos a La Marquesa con unos primos!"), esgrimiendo la existencia del embarazo y, por ello, su dominio incuestionable sobre ella (Me decía "Te vas a quedar conmigo porque ya estás embarazada, tú eres mi mujer").

(2) Por problema con la madre. A Ángela le dijo su madre que bien podría irse de casa si no estaba conforme con las reprensiones (Si te gusta mamacita, si no ahi está la puerta) que le hacía por su nueva conducta ( Ya no quieres hacer nada!, ¡Todo el tiempo te la pasas en la calle!, y ni siquiera lavas tu ropa"), que era común después del festejo de XV años. Así relató su partida:

La niña berrinchuda (o sea, ella misma) fue y le dijo a su novio que (su mamá) ya la había corrido (...). Él era muy celoso. Le dije “(...) me voy a ir a quedar (...) con mi tía, la que conoces" (...), y él fue así de "(...) no te vas a ir con ella, seguramente te vas a ir con tus amigos" (...). Me invitó a quedarme en su casa. Cuando llegamos les dijo a sus papás que si me daban chance de quedarme (...). (Ya) con mi mamá, él le dijo "(...) yo me quiero casar con su hija y ya su hija se va a quedar a vivir conmigo" (...). Y entre tanta palabra (...) él le pidió mi mano a mi mamá (...), y mi mamá le dijo que si era en serio o era nada más un capricho (...). Me salí con las mías y me vine.

Mayte, tras su primera llegada a casa a las 12 de la noche, fue regañada por su madre y bofeteada por su padrastro, por lo que tuvo un fuerte disgusto. El novio de Mayte la invitó a quedarse en casa de él, lo que ella aceptó. Determinó juntarse con su novio por una serie de hechos que le parecieron indignantes: tras la salida de casa su madre presentó una demanda penal contra el novio por encierro y violación supuestos (Ni me forzó a irme ni abusaba de mi porque todo lo que pasó fue por consentimiento mío $y$ de él); después de la consignación judicial sufrió los trámites hechos en el Ministerio Público (interrogatorio; inspección corporal, por parte de personal masculino, con autorización de la madre, para confirmar o descartar violación); y enojo contra su madre por su oposición inicial a otorgarle perdón penal al novio ("Si tú no levantas el perdón olvídate de que yo regrese contigo a la casa"). Le otorgó el perdón inútilmente (¿De qué sirvió si al otro día me volví a ir con él?). 
(3) Por amenaza y temor. $J$ escapó de casa con su novio. Lo hizo temerosa de su madre y amedrentada por él, interesado en que se juntaran. Recordó aquello, con ojos llorosos: Me dijo que nos fuéramos, que si no su mamá iba a venir a hablar con mi mamá. Yo le tenía mucho miedo a mi mamá.

\section{Trato restrictivo al vivir juntada}

La vida, juntados, fue poco llevadera, salvo lo vivido por Estrella (¡Cumplimos un año, juntos, ya tan rápido!) que quedó embarazada antes de juntarse con su novio, en casa del padre de éste. Una vez juntadas, las adolescentes comenzaron a cumplir obligaciones domésticas y conyugales si lo permitía su salud como embarazadas. Lo más común fue el desacuerdo o el conflicto de pareja. Con el paso del tiempo algunas comenzaron a sufrir inhospitalidad o enemistad de la familia del novio (Elsa, Yaeni); restricciones en el empleo de espacios y enseres domésticos y faltas en el cuidado de la salud por embarazo (Yaeni); insultos y golpes (Martha y Ángela); encierro doméstico (J, Mayte y Martha); aislamiento social e impedimentos por celos ( $J$, Elsa, Mayte, Estrella, Ángela, Martha); privación económica (Elsa, Yaeni, Estrella, Martha), deslealtad conyugal (Mayte, Martha, Ángela), acrecentados por el alcoholismo de alguna pareja (la de Martha); negligencia por actividades lúdicas del novio inmaduro (Yaeni); o violencia que se creyó merecida (Ángela).

Considérese específicamente el caso de Mayte. Para ella la vida, juntados, que los primeros meses fue de alegría y amor se tornó más restrictiva y carente de lealtad conyugal (él decía "No soy de una sola mujer"), y prohibiciones de visitar a la familia y comunicarse con amigos. Embarazarse y juntarse le pareció factible (Yo lo veía así con mis hermanas que venían sus novios y los atendian, y se iban, y se quedaban. Se me hizo fácil hacer lo mismo). Sería un escape (Una vez que lo estábamos haciendo le dije "Vamos a tener un hijo porque yo ya tenía muchos problemas en casa). Sin embargo, dado lo ocurrido después (Me pegaba, no me dejaba salir. Se iba a tomar y me dejaba y llegaba a las tres, cuatro de la mañana), resultó ser una mala elección (Desgraciadamente yo elegí mal y no sabía la persona que era. ¡Ay! ¡Muy triste! ¡Ay! —llanto). Sus suegros la mantuvieron económicamente y pudieron defenderla en algunos actos violentos de su pareja. Decidió no volver a su hogar con vergüenza y sentimiento de culpa por haber desoído las frecuentes advertencias. Después descubrió que su pareja se había juntado antes, también en la casa de sus padres, con otra chica que embarazó. 


\section{Descubrimiento del estado de embarazo}

Para cuatro participantes fue poco evidente el comienzo del embarazo, más si siguieron menstruando (Mayte y Estrella). Fueron mujeres cercanas y experimentadas quienes las ayudaron a obtener certeza de éste: madre (Estrella), abuelas (Mayte y Yaeni) y suegra (Ángela). Las otras tres participantes (J, Elsa y Martha), que dejaron de menstruar, sí identificaron los signos de embarazo.

La sintomatología incluyó: sensación de rareza (Yaeni, $J$ y Elsa), dormir más que lo habitual (Yaeni, Estrella y Elsa), ascos (Yaeni, Estrella y $J$ ), vómito (Ángela, Estrella, $J$ ), pereza (Elsa y Estrella), inapetencia (Yaeni), agruras $(J)$, repulsión a perfumes $(J)$, aumento de talla (Elsa), un cuadro sintomático similar en el compañero $(J)$, y cólicos intensos previos a diagnóstico de amenaza de aborto (Estrella). Los signos percibidos por las abuelas fueron: cara de embarazada, matriz ocupada declarada después de pulsarle el vientre (Mayte), ojos y mirada de embarazada y tener algo raro (Yaeni). Todas las participantes, su pareja y su parentela, interesados en tener certeza del embarazo, requirieron las pruebas de embarazo conocidas: de orina (la de farmacia y la laboratorio), sanguínea y ultrasonografía. Veamos dos ejemplos de las formas de descubrimiento del embarazo:

(1) Estrella ignoraba que estaba embarazada - a sus catorce años de edad, siendo estudiante de secundaria y teniendo unos cuatro meses de noviazgo - porque seguía menstruando. Su madre advertía que dormía mucho, expresaba pereza, sentía ascos y vomitaba. Por ello le ordenó hacerse una prueba de embarazo. El resultado de la prueba de orina fue positivo (Se marcaron las dos rayitas... Me puse a llorar y mi mamá también y mis tíos también). La madre furiosa informó del hecho al novio recién llegado (Le dijo "Ten, te entrego la prueba de embarazo"... "Mi hija desde hoy es tu responsabilidad"). Éste se vio desconcertado. De momento su padre la evitaba a ella y al muchacho. Después, por intervención de la esposa, ofreció apoyo a su hija deprimida.

(2) Martha y su novio suspendieron el uso del condón. Pronto ella notó que ya no menstruó. Obedeció a su pareja y se realizó tres pruebas de embarazo, en este orden: de sangre, de orina y ultrasonido, con resultados positivos. No erró en que su madre y sus hermanos la reprenderían al confesar el embarazo porque rechazaban al novio por su actitud desobligada e improductiva. 


\section{Decisión de continuar el embarazo}

Las siete participantes tomaron la decisión final de seguir el embarazo confirmado. Estrella y Yaeni, y sus compañeros, tuvieron siempre la convicción de continuarlo. Incluso Ángela, que vivía con resignación la violencia de su pareja, tomó el embarazo como algo radical e intocable. Dos rechazaron la opción de aborto contemplada por el compañero y la madre, respectivamente.

Elsa: Me dijo “¿Quieres abortar o quieres tenerlo?”. Le digo “No, ¿cómo voy a abortar a mi hija? (...). No tengo el corazón, primero ando de loca". Dice "La decisión que tú tomes, yo te voy a apoyar".

Martha: Mi mamá (...) me decía que no lo tuviera, que me fijara en la edad que tenía como para que yo tuviera un hijo (...). Pero nunca tuve (...) buena comunicación con mi mamá (...). Era de trabajar, "Ten tranquizas" y "No hiciste esto, no hiciste lo otro" y ya a dormir (...). Me decía que no lo tuviera o que me quedara a vivir aquí si yo iba a decidir (tenerlo) (...), pero no quise y me fui a vivir con él.

Martha, aconsejada por su hermana, había abortado antes mediante consumo de pastillas, sufriendo experiencias que no quiso repetir abortando de nuevo.

Mayte $y J$ sí pensaron en el aborto, pero sus novios no lo aprobaron. Mayte, aun sintiéndose demasiado joven a sus 15 como para embarazarse, aceptó continuar el embarazo para complacer a su novio encantado de tener un bebé. A los siete meses de embarazo comprendió la insistente sugerencia materna de que abortara, pero ya no era médicamente oportuno hacerlo. Lamentaba: "Se me va a cerrar todo, ya con un hijo, nada de libertinaje”... “¿Una niña cuidar a un niño!”. $J$, que dudaba continuar el embarazo, consiguió con su tía pastillas abortivas, pero no las ingirió debido a: (1) la vigilancia de su pareja, emocionado por el embarazo y disgustado con ella porque contemplaba abortar y (2) la oposición de su madre al aborto, idea que ella adoptó más tarde (Yo no la quería tener y ya después: "Los niños no tienen la culpa").

\section{Discusión}

Analizamos el origen gradual del embarazo temprano, pero concordamos con estudios que muestran algunos de sus factores: el tipo de educación sexual recibida (Kohler, Manhart y Lafferty, 2008), la comunicación omisa con los padres sobre el tema (Duberstein Lindberg, Maddow-Zimet, 
y Boonstra, 2016); el nivel socioeconómico bajo (Nyakubega, 2009); la pobreza y la influencia de pares (Gyan, 2013); la pobreza y las creencias de los padres sobre reproducción y sexualidad (Yadufashije, Sangano y Samuel, 2017); el nivel educativo bajo de la mujer joven (Welti, 2000); el tamaño de la localidad de residencia y la condición étnica (Welti, 2012); la migración rural-urbana y las relaciones familiares disfuncionales (Panting, Abdullah, Roslan e Ismail, 2019); la curiosidad, dificultades financieras, conflictos familiares y emociones fuera de control (Pogoy, Verzosa, Coming y Agustino, 2014). Asumimos que esos factores son causas o efectos dependiendo de situaciones, interpretaciones, negociaciones y participaciones de las adolescentes, su pareja, la parentela y otros.

En congruencia con Rubin (1986), Lagarde (1997), Cazés (2000) y Bourdieu (2000), afirmamos que las mujeres del estudio se implicaron en: prácticas amorosas, eróticas y sexuales, y una unión de pareja y un embarazo a sus 14 o 15 años de edad, bajo condiciones de dominación masculina. El embarazo es un fenómeno biológico que involucra el cuerpo de las mujeres (Mothiba y Maputle (2012), pero también el de los hombres. Su origen se contextualiza sociocultural y psicológicamente. Según la categoría de mundos intencionales de Shweder (1990), el embarazo temprano puede concebirse como un mundo intencional, esto es, como una realidad sociocultural que existe en una comunidad de personas en virtud de sus prácticas, significados, deseos, emociones y propósitos. Por ser un mundo intencional es artificial, producto de diseño humano: chicas e individuos participan en él, y son afectados por éste, dados los significados que (se) le atribuyen.

Nuestra comprensión cualitativa, holística, inductiva (Taylor y Bogdan, 1996) de lo ocurrido a mujeres en su adolescencia temprana, respecto del origen de su embarazo, supuso analizar sus relatos para situarlo social y biográficamente. Describimos: momentos de intersección de su trayectoria de vida con la de otras personas, secuencias de conductas y acontecimientos significativos, distintos contextos y escenarios vitales, y las intencionalidades que las aproximaron, desde su niñez, al embarazo. El método empleado y el enfoque de género hicieron visibles la actuación de las adolescentes en torno a la concepción, en su mundo patriarcal sexista, pero también la de quienes las preñaron y otros agentes sociales. Consideremos la siguiente secuencia identificada. 


\section{Noviazgo: mundo en constitución patriarcal desde la niñez}

Cada embarazo tuvo lugar en un sendero de noviazgo, cuyas prácticas y significados comenzaron a ser aprendidas por hombres y mujeres desde su infancia, incluso en el nivel preescolar. En la escuela primaria, el noviazgo vivido incluyó estar y caminar juntos, abstraídos del entorno, darse obsequios ad hoc. En la escuela secundaria hubo contacto corporal más erotizado, fenoménico e íntimo (mirarse, extrañarse, buscarse, abrazarse, acariciarse, besarse, toquetearse, quizá iniciarse sexualmente). En el bachillerato el magreo y el sexo fueron más definitivos. Así, la inserción de las mujeres en relaciones de noviazgo, con sus prácticas de implicación cada vez más íntima, aparece como precursora del posible embarazo temprano. Los espacios fueron la escuela, el vecindario, la calle, parques y canchas. Sus escenarios fueron las fiestas, paseos, fugas de la escuela, juegos y bailes. Hermanas, primas, tías y amistades facilitaron la unión. Los medios ordinarios de la declaración fueron cartas, recados, teléfono y Facebook. Padres y parientes de la chica fueron los vigilantes de su noviazgo, frenando o imponiendo conductas, procurándoles con éxito parcial uniones con varones convenientes, según preceptos y deseos del imaginario patriarcal, como el desideratum (Cazés, 2000) y el cautiverio materno-conyugal (Lagarde, 1997), selectividad que, asumida de manera activa (práctica y simbólica) por la chica y su pareja, podría ser precursora del embarazo.

\section{Resistencia o aceptación femenina al cortejo masculino: el "sí"}

A los hombres correspondió cortejar a las mujeres desde que eran niñas. Parte de su cortejo fue la declaración, la petición, de ser pareja. Ellas dieron el "sí" dependiendo de su deseo, y de la tenaz insistencia masculina aún si obtuvieran poco beneficio. Cuando ellas mostraron primero su interés fueron censuradas o ellas mismas se criticaron. El noviazgo es exclusivo, pero es factible que cualquiera de los dos o ambos engañen, sean desleales al otro. Un noviazgo aburrido, una ruptura sugerida por el nuevo pretendiente, la osadía o el hostigamiento de éste, o haber sufrido un despecho llevaron a las chicas a una nueva relación de noviazgo, a veces simultánea. El "sí" de la adolescente tornó la relación en noviazgo — con su consabida actividad afectiva, erótica e inclusive sexual — constituyendo otro acercamiento psicosocial a su embarazo potencial. 


\section{El permiso paterno}

Pasada la pubertad, el noviazgo estipula para las novias la posibilidad, respecto de sus novios, de dar y recibir compañía, comunicar sentimientos, tener contacto corporal íntimo. Las adolescentes actuaron bajo este orden sin informar ni contar con la autorización de sus padres. De haber interés del novio, éste pidió permiso a los padres de andar con ella públicamente, con mayor seriedad y compromiso. El permiso fue un logro de madurez social y psicológica para la pareja. Significó una concesión de poder de los padres al novio sobre la hija bajo el deber supuesto de protegerla y darle cariño, trato galante y respeto sexual. El permiso aflojó la atadura del espacio/ tiempo doméstico de la adolescente y le autorizó conducta íntima y erótica moderada, la cual en los hechos, cuando se burló la vigilancia adulta y social — lo que fue fácil — propició encuentros sexuales que, sin prevención anticonceptiva, podrían culminar en embarazo. El permiso utilizado sería otro acontecimiento, o eslabón, en el noviazgo y la trayectoria de vida, que podría conducir al embarazo temprano.

\section{Menarquia y edad de 15 años: marcas para nuevas etapas sexuales}

La menarquia y otros cambios (crecimiento de senos y caderas) de la maduración sexual biológica y la ceremonia de XV años abrieron nuevas etapas en la vida social de las mujeres. La menarquia demandó a las madres explicar a sus hijas el uso discreto de toallas sanitarias durante el período menstrual, alertarlas de que su implicación coital ya podría ser fértil y vigilarlas para evitarles embarazos. Una fiesta de XV años difunde en la comunidad que la muchacha ya puede tener pareja o una pareja más formal. En su respectivo sentido, ambos eventos fueron mundos intencionales constituidos colectiva e individualmente (Shweder, 1990) en materias de sexualidad, reproducción, pareja y familia. Tras ellos podrían ya resultar embarazadas las adolescentes; sugieren el cuándo, con quién, dónde, cómo, por qué y para qué, según los guiones sexuales de Gagnon (1980). Son condiciones incluidas en el desiderátum o deseos sociales sobre los sexos (Cazés, 2000) para que algunos hombres (los novios con permiso) obtengan beneficio sexual en la sociedad patriarcal sobre mujeres adolescentes ya fértiles, acatando el sistema de parentesco (Rubin, 1986). Brevemente, los dos eventos refirieron la posibilidad circunstanciada del coito vaginal fecundo y el embarazo temprano. 


\section{Iniciación sexual incitada por el novio}

El noviazgo permitido respaldó mayor cercanía corporal de la pareja. Esta proximidad, instigada por el novio, antecedió al primer acto coital, también incitado por él, como observó Kiluvia (2011). Otro elemento de estas conductas fue la anuencia de la novia, por situaciones, circunstancias o motivaciones personales, afectivas y sexuales, en escenarios específicos. La baja autoestima de la adolescente también propició su iniciación sexual, como mencionaron Mothiba y Maputle (2012). Ésta ocurrió por vivir una relación percibida sin abandono ni engaño (Ángela); se hizo con el otro por despecho, en un lugar apartado, dado el impulso sexual del momento (Estrella); o se aceptó siendo engatusada (él me lavó el coco) y estando enamorada (Martha). Así, ser responsiva a la envestida verbal y erótica de la pareja es una actitud que aproxima al debut sexual y al probable embarazo.

\section{Protección anticonceptiva en la iniciación sexual}

En el acto de iniciación sexual de las siete participantes, el novio tuvo que usar condón como medida anticonceptiva, condición impuesta por ellas o acordada por ambos. Su virginidad les otorgó poder en la negociación exitosa del uso del condón. La utilización del preservativo implicó para ellas aceptar la finalización de su virginidad, valorada por su moral religiosa, pero también evitar el embarazo, asunto estimado de mayor relieve. En congruencia con hallazgos de otros autores (Mothiba y Maputle, 2012; Panting, Abdullah, Roslan e Ismail, 2019), que consideran al desconocimiento sobre anticoncepción como factor del embarazo adolescente, nuestras participantes, informadas en la escuela y/o por la madre sobre el tema, sí supieron cómo protegerse en su iniciación sexual y técnicamente lograron evitar el embarazo. Así, la iniciación sexual protegida anticonceptivamente observada es buena señal para educadores y planeadores en salud sexual y reproductiva. Sin embargo, fue precursora de encuentros sexuales con protección anticonceptiva inconsistente por distintas intenciones que conducirían por igual al embarazo.

\section{Conocimiento y renuencia en materia de anticoncepción}

En las relaciones sexuales posteriores fue infrecuente el uso del condón, único medio anticonceptivo considerado, a pesar de que ellas conocían bien esa valiosa función y la existencia de otros métodos análogos menos accesibles (píldora, DIU). Así, la fecundación ocurrió, no por ignorar esa materia, sino por la práctica de sexo no protegido por aspectos interper- 
sonales, afectivos y sensuales, propios de la cultura sexista asimilada, la cual es similar en ello a la de Tanzania (Kiluvia, 2011). En los encuentros sexuales sin condón aparecieron la indiferencia, la osadía y el exceso de confianza en connivencia con el novio renuente, o la esperanza unilateral de éste de tener un hijo, o el deseo compartido de un embarazo instrumental para poder juntarse. Estas actitudes, y los significados concomitantes, tuvieron un papel en los actos sexuales que provocarían el embarazo. Restricciones sufridas por ellas en la familia y el sector salud, por minoría edad, les impidieron acceder a medios anticonceptivos que pudieron haber empleado. Empero, su embarazo tuvo más qué ver con su débil poder psicopolítico, por ser mujeres muy jóvenes, que con su falta de conocimientos técnicos sobre anticoncepción. Aun así, la disponibilidad y el conocimiento de los métodos anticonceptivos son imprescindibles.

\section{Develación del embarazo adolescente: agentes y medios}

Hubo casos en que las parientes mayores y más experimentadas, en eventos sexuales y reproductivos, tuvieron antes que ellas la sospecha de embarazo. Otras sí identificaron la sintomatología típica (amenorrea, fatiga, vómito) como indicio importante. Todas las participantes, sus compañeros y la parentela próxima de cada integrante de la pareja requirieron de datos certeros de las pruebas de embarazo: de orina, de sangre y ultrasonografía. De modo peculiar, a $J$ los síntomas tipo Couvade de su pareja (Brennan, Ayers, Ahmed y Marshall-Lucette, 2007; Ganapathy, 2015) le ayudaron a identificar el embarazo. En general, la secuencia de hechos sobresaliente fue: sexo sin protección anticonceptiva, fecundación inadvertida, presencia de signos y síntomas de embarazo, su detección incierta por las chicas o por mujeres mayores cercanas a ellas, pruebas de embarazo con resultados confiables y reconocimiento firme del estado de embarazo. Resultó una gran diferencia social y psicológica entre el embarazo biológico aún inadvertido y el embarazo ya diagnosticado y significado como tal.

\section{Descarte del aborto}

Así como Gyesaw y Ankomah (2013) encontraron en Ghana que se recurre poco al aborto, y Aparicio, Vanidestine, Zhou, y Pecukonis (2016) hallaron en Maryland que a mujeres latinas su comunidad les desaprueba abortar, nuestras participantes decidieron continuar su embarazo. Tres jamás pensaron siquiera en el aborto (Estrella, Yaeni y Ángela), dos rechazaron su posibilidad sugerida por el novio y la madre (Elsa y Martha) y dos pensaron hacerlo, pero desistieron: $J$ para terminar el disgusto de su 
pareja porque contempló esa posibilidad, Mayte para complacer al varón deseoso de tener un bebé, ambas porque su madre se oponía al aborto. Así, la continuación del embarazo fue situada y objeto de negociaciones en la pareja y la familia, donde terminaron imponiéndose ideas, sentimientos y emociones sobre maternidad y paternidad, y creencias en la existencia de vida humana durante la gestación uterina, bien asimiladas a esta altura de la adolescencia.

\section{Embarazo, expulsión o chantaje: motivos para juntarse}

Las participantes tuvieron tres motivos para abandonar el hogar familiar y juntarse con sus novios: (1) el embarazo, (2) conflictos por desacato a la autoridad de los padres y (3) intimidación del novio y temor a la madre. Así, la salida de casa fue una sustracción, una expulsión o una huida confabulada de las jovencitas que así dejaron atrás el control familiar e ingresaron al dominio, parcialmente desconocido, del novio con quien se juntaron. En términos de Lagarde (1997), a fin de cuentas salieron de un cautiverio para entrar a otro sin sospecharlo, del de hija al de concubina menor de edad, al que llegaron embarazadas o susceptibles al embarazo.

\section{Sufrimientos de las adolescentes, juntadas y embarazadas, en su nuevo cautiverio}

Una vez juntadas, las adolescentes, alojadas en un cuarto de la casa de los padres del novio, comenzaron a cumplir obligaciones domésticas y conyugales, si lo permitía su salud como embarazadas. Lo más común fue el desacuerdo o el conflicto de pareja. Con el paso del tiempo algunas comenzaron a sufrir: inhospitalidad o enemistad de la familia del novio; restricciones en el uso de espacios y enseres domésticos; faltas en el cuidado de la salud por embarazo; insultos y golpes (Martha y Ángela); encierro doméstico; aislamiento social e impedimentos por celos; privación económica; deslealtad conyugal y negligencia por actividades lúdicas del novio inmaduro (Yaeni). Ángela sufrió de violencia simbólica, en el sentido planteado por Bourdieu (2000) de creer que se merecía los tratos adversos. Algunos suegros fueron protectores y solidarios con la nuera agraviada (Martha). Los abusos machistas contra las adolescentes fueron peores en las condiciones de menores, juntadas y embarazadas, que mermaron su poder de actuación en los ámbitos domésticos de subordinación femenina (Lagarde, 1997).

La serie de eventos recién descrita, de mundos intencionales entrelazados, consecutivos, que devinieron en el embarazo adolescente, ciertamente 
no es la única que tiene lugar en nuestro país, con tal desenlace. Así, futuros estudios podrían analizar otros procesos donde se produce el embarazo adolescente, verbigracia, tras arreglo o consenso, fallas anticonceptivas, abuso, incesto o violación. Esta variedad quizá se incorporó, aunque permaneció indiferenciada, en datos estadísticos como los analizados por Welti $(2000 ; 2012)$ y Arceo y Campos (2014) y los aportados por el INEGI (2019).

El embarazo adolescente no es un evento uniforme ni aislado, sino diverso, que es producido, vivido y significado eventualmente como problemático. Por ello, pensamos que su prevención o atención demandan intervenciones en dos niveles: el macroscópico, en cuanto a diseño de marcos jurídicos y políticas educativas, sanitarias y familiares que propicien una cultura general de mayor equidad intergenérica y corresponsabilidad, en materias de conocimientos, afectividad, sexualidad y reproducción; y el microscópico, en cuanto a formas de trato específicas y significativas dirigidas a las personas implicadas actual o potencialmente, de manera directa o indirecta, en el embarazo adolescente, considerando lo que Dreier (1999) concibió como: trayectorias de vida personal, ubicación contextual (lugares cotidianos), posición social (relación con los otros) y postura (comprensiones y puntos de vista).

\section{Conclusiones}

El embarazo temprano fue precedido por la participación de las jóvenes y sus pretendientes en varios mundos intencionales dentro de la sociedad patriarcal sexista, de subordinación femenina: el orden familiar, la división sexual del trabajo y otras tareas, la vida escolar, la amistad, el noviazgo, el contacto físico íntimo, la maduración psicosexual, algunos eventos sociales, las prácticas sexuales, el manejo anticonceptivo y las creencias y saberes sobre la vida intrauterina.

El acto sexual fecundo tuvo antecedentes biológicos, psicológicos y sociales. Ellas, como agentes en su trayectoria de vida personal, tuvieron aprendizajes situados previos tanto prácticos como afectivos y discursivos: la pareja es una relación emocional valiosa y habitual; las mujeres son más restringidas en lo erótico-sexual que los hombres; ellas responden a los deseos y requieren de las decisiones, protección y conducción del hombre en varias áreas, incluida la sexual; los quince años o una edad cercana las autoriza a la intimidad y el coito vaginal; su participación en este último es privada, pero censurable; ellas pueden esquivar la vigilancia social y paternal que pugna por su abstinencia sexual; se conoce la protección anti- 
conceptiva, pero hay cálculos, circunstancias e impulsos que la hacen prescindible; el noviazgo permitido suele preceder al concubinato; mantenerse virgen o sin hijos hasta el matrimonio es un deseo familiar que no siempre se satisface; la función maternal es principal para las mujeres y para los hombres la función laboral, las dos dificultadas si ambos son menores, pobres y sin estudios avanzados; el embarazo obliga a, o permite, la salida de la casa familiar y la unión conyugal de las menores; y esta última, aunque temprana, propicia el embarazo.

Este origen psicosocial del embarazo temprano, que documentamos a partir de la experiencia común relatada por las participantes, incluyó varios componentes complejos convencionales, en la localidad. Asimismo, es previsible que en estudios futuros se logre dar cuenta de otros procesos psicosociales y circunstancias típicas, ausentes en nuestro estudio, que también conducen al embarazo temprano. Por ello, sugerimos lecciones y discusiones en la familia y la escuela, con respeto y equidad para infantes y adolescentes de uno y otro sexo, que contemplen otros temas y no sólo la biología reproductiva, los métodos anticonceptivos y la abstinencia sexual. Se requieren políticas públicas que lo prevengan, o que de suceder permitan su interrupción o su continuación voluntaria, informada, oportuna y segura, y ayuden a afrontar las consecuencias atendiendo a las necesidades y responsabilidades de las y los involucrados: favorecer su desarrollo psicosocial, su permanencia en la escuela, de ser el caso, y su bienestar económico.

Finalmente, el origen del embarazo descrito provino de la perspectiva de las mujeres, más delante se podría considerar la de los varones, o ambas comparativamente.

\section{REFERENCIAS BIBLIOGRÁFICAS}

Álvarez-Gayou Jurgenson, Juan Luis, 2007, Cómo hacer investigación cualitativa. Fundamentos y metodología. México, Paidós.

Anda, Robert F.; Chapman, Daniel P.; Felitti, Vincent J.; Edwards, Valerie; Williamson, David F.; Croft, Janet B.; and Giles, Wayne H., 2002, "Adverse childhood experiences and risk of paternity in teen pregnancy", in Obstetrics and Gynecology, 100 (1), 37-45. Disponible en http://www.theannainstitute.org/ACE\%20 folder $\% 20$ for $\% 20$ website/33ARPT.pdf

Aparicio, Elizabeth M.; Vanidestine, Todd; Zhou, Kelly; and Pecukonis, Edward V., 2016, "Teenage pregnancy in latino communities: young adult experiences and perspectives of sociocultural factors. Families in society", in The Journal of Contemporary Human Services, 97(1), 50-57. Disponible en 10.1606/10443894.2016.97.3. 
Arceo-Gomez, Eva; Campos-Vazquez, O. and Raymundo M., 2014, "Teenage pregnancy in Mexico: evolution and consequences", in Latin American Journal of Economics, 51 (1) 109-146. DOI: 10.7764/LAJE.51.1.109. Disponible en https:// scielo.conicyt.cl/pdf/laje/v51n1/art04.pdf

Birech, Jeniffer, 2013, “Child marriage: a cultural health phenomenon. International", in Journal of Humanities and Social Science, 3 (17), 97-103. Disponible en http://www.ijhssnet.com/journals/Vol_3_No_17_September_2013/12.pdf

Bourdieu, Pierre, 2000, La dominación masculina. Barcelona: Anagrama.

Brennan, A., Ayers, S., Ahmed, H. and Marshall-Lucette, S., 2007, “A critical review of the Couvade syndrome: the pregnant male", in Journal of Reproductive and Infant Psychology, 25(3), pp. 173-189. doi: 10.1080/02646830701467207.

Cazés, Daniel, 2000, La perspectiva de género: Guía para diseñar, poner en marcha, dar seguimiento y evaluar proyectos de investigación y acciones públicas y civiles. México: CONAPO y Consejo Nacional de la Mujer.

Dreier, Oleg, 1999, “Trayectorias personales de participación a través de contextos de práctica social", en Pérez Campos, Gilberto, Alarcón Delgado, Irma de Lourdes, Yoseff Bernal, Juan José y Salguero Velázquez, María Alejandra, Psicología Cultural. Vol. 1 (pp. 81-128). México: Universidad Nacional Autónoma de México. Facultad de Estudios Superiores Iztacala.

Duberstein Lindberg, Laura; Maddow-Zimet, Isaac; and Boonstra, Heather, 2016, "Changes in adolescents' receipt of sex education, 2006-2013", in Journal of Adolescent Health, 58, 621-627. Disponible en file://C:/Users/Salvador/AppData/ Local/Packages/Microsoft.MicrosoftEdge_8wekyb3d8bbwe/TempState/Downloads/Changes_in_Adolescents_Receipt_of_Sex_Education_2\%20(1).pdf

Gagnon, John, 1980, Sexualidad y conducta social. México: Pax.

Ganapathy, Thilagavathy, 2015, "Couvade syndrome among 1st time expectant fathers", in Muller Journal of Medical Science and Research, 5(1), 43-47. Disponible en file://C:/Users/Salvador/AppData/Local/Packages/Microsoft. MicrosoftEdge_8wekyb3d8bbwe/TempState/Downloads/Couvade_syndrome_ among_1_st_time_expectant_fathers\%20(1).pdf

Gyan, Charles, 2013, “The effects of teenage pregnancy on the educational attainment of girls at Chorkor, a suburb of Accra", in Journal of Educational and Social Research, 3 (3), 53-60. Doi:10.5901/jesr.2013.v4n3p53.

Gyesaw, Konadu; and Ankomah, Augustine, 2013, "Experiences of pregnancy and motherhood among teenage mothers in a suburb of Accra, Ghana: a qualitative study", in International Journal of Women's Health, 5 (1): 773-80. DOI: 10.2147/ IJWH.S51528.

Habitu, Yohannes Ayanaw; Yalew, Anteneh; and Bisetegn, TelakeAzale, 2018, "Prevalence and factors associated with teenage pregnancy, Northeast Ethiopia, 2017: a cross-sectional study", in Journal of Pregnancy, vol. 2018, Article ID 1714527, 7 pages. https://doi.org/10.1155/2018/1714527. 
INEGI, 2019, Natalidad y fecundidad. Instituto Nacional de Estadística y Geografía, Disponible en https://www.inegi.org.mx/temas/natalidad/

Hernández Sampieri, Roberto; Fernández Collado, Carlos; Baptista Lucio, María del Pilar, 2010, Metodología de la Investigación. México: McGraw-Hill.

Kiluvia, Fatima Sunny, 2011, "Gender and sexuality notions as determinants of school pregnancies in Tanzania: a case of Iringa rural district", in Master Of Arts In Development Studies. Holanda: International Institute of Social Studies. Graduate School of Development Studies. 61 páginas. Disponible en https://pdfs.semanticscholar.org/1440/fbd54eb55ca92c182d1abff30371e48a3173.pdf

Kohler, Pamela K.; Manhart, Lisa E.; Lafferty, William, E., 2008, “Abstinence-only and comprehensive sex education and the initiation of sexual activity and teen pregnancy", in Journal of Adolescent Health, 344-351. Disponible en http://www. ministryoftruth.me.uk/wp-content/uploads/2012/12/PIIS1054139X07004260.pdf

Lagarde, Marcela, 1997, Los cautiverios de las Mujeres: madresposas, monjas, putas, presas y locas. México: Universidad Nacional Autónoma de México.

Maputle, D. Cur, 2006, "Becoming a mother: teenage mothers' experiences of first pregnancy", in Curationis 29 (2): 87-95. Disponible en https://pdfs.semanticscholar.org/4f2b/0d13783377e29f57e1582e8d6a7905e4fe48.pdf

Mothiba, T.M. and Maputle, MS., 2012, "Factors contributing to teenage pregnancy in the Capricorn district of the Limpopo Province", in Curationis 35(1), Art. 19, 5 pages. http:// dx.doi.org/10.4102/ curationis.v35i1.19. Disponible en https:// www.ncbi.nlm.nih.gov/pubmed/23327768

Nyakubega, Peter, 2009, "Factors associated with adolescent pregnancies among secondary school students. A study from Tanga-Tanzania", in Official Publication of the Tanzania Medical Students' Association 2008/2009, 31-33. Disponible en https://www.ajol.info/index.php/dmsj/article/viewFile/53350/41928

O’keeffe, Jimmy; Buytaert, Wouter; Mijic, Ana; Brozović, Nicholas; and Sinha, Rajiv, 2016, "The use of semi-structured interviews for the characterization of farmer irrigation practices”, in Hydrol. Earth Syst. Sci., 20, 1911-1924. Disponible en https://www.hydrol-earth-syst-sci.net/20/1911/2016/hess-20-1911-2016.pdf

Panting, Albeny Joslyn; Abdullah, Haslinda; Roslan, Samsilah; and Ismail Ismi Arif, 2019, "Potential social risk factors for teenage pregnancy in Sarawak", in Pertanika Journal of Social Science and Humanities. 27 (1): 425 - 441. Disponible en https://pdfs.semanticscholar.org/cf78/ad91ec0b5fec148e79d4bc006fdb174deddc.pdf

Pogoy, Angeline M.; Verzosa, Rustica; Coming, Nerlie, S.; Agustino, Ronalissa G., 2014, "Lived experiences of early pregnancy among teenagers: a phenomenological study", in European Scientific Journal, 10 (2), 157-169. Disponible en https:// www.academia.edu/9740205/LIVED_EXPERIENCES_OF_EARLY_PREGNANCY_AMONG_TEENAGERS_A_PHENOMENOLOGICAL_STUDY

Rubin, Gayle, 1986, "El tráfico en las mujeres: notas acerca de la economía política del sexo", en Nueva Antropología, vol. 8, núm. esp. 30, 95-145. 
Santelli, John S.; Kantor, Leslie M.; Grilo, Stephanie A.; Speizer, Ilene S.; Lindberg, Laura D.; Heitel, Jennifer; Schalet, Amy T.; Lyon, Maureen E.; Mason-Jones, Amanda J.; McGovern, Terry; Craig, J. Heck; Rogers, Jennifer; and Ott, Marry A., 2017, "Abstinence-only-until-marriage: an updated review of U.S. policies and programs and their impact", in Journal of Adolescent Health 61, 273-280. Disponible en http://dx.doi.org/10.1016/j.jadohealth.2017.05.031.

Shweder, Richard A., 1990, "Psicología cultural ... ¿Qué es ?”, en Pérez Campos, Gilberto ; Alarcón Delgado, Irma de Lourdes ; Yoseff Bernal, Juan José ; y Salguero Velázquez, María Alejandra, 2013, Psicología Cultural. Volumen 1 (pp. 1-42). México: Universidad Nacional Autónoma de México. Facultad de Estudios Superiores Iztacala.

Stern, Claudio, 1997, "El embarazo en la adolescencia como problema público: una visión crítica”, en Salud Pública de México, 39 (2), 137-143.

Taylor, SJ. y Bogdan, R., 1996, Introducción a los Métodos Cualitativos de Investigación. México: Paidós.

Vela Peón, Fortino, 2004, “Un acto metodológico básico de la investigación social: la entrevista cualitativa", en Tarrés, M.L. (ed.), Observar, escuchar y comprender sobre la tradición cualitativa en la investigación social (pp. 63-95). México: FLACSO, El Colegio de México, Porrúa.

Welti Chanes, Carlos, 2000, “Análisis demográfico de la fecundidad adolescente en México”, en Papeles de Población, 6 (26), 43-87. Disponible en https://www. scielo.org.mx/scielo.php?script=sci_arttext\&pid=S1405-74252000000400004

Welti Chanes, Carlos, 2012, “Análisis de la fecundidad en México con los datos del Censo de Población y Vivienda 2010”, en Papeles de Población, vol. 18, núm. 73. Disponible en http://www.scielo.org.mx/scielo.php?script=sci_arttext\&pi$\mathrm{d}=\mathrm{S} 1405-74252012000300004$

Yadufashije, Callixte; Sangano, George Bahati; Samuel, Rebero, 2017, “The study of factors influencing teenagers pregnancy in Africa", in International Journal of Interdisciplinary Innovative Research and Development. 2 (1), 13-18. Disponible en https://www.academia.edu/34546084/THE_STUDY_OF_FACTORS_INFLUENCING_TEENAGERS_PREGNANCY_IN_AFRICA

\section{RESUMEN CURRICULAR DE LOS AUTORES}

\section{José Salvador Sapién López}

Doctor en Antropología por la Escuela Nacional de Antropología e Historia (con Mención Honorífica), Maestro en Psicología y Licenciado en Psicología por la Universidad Nacional Autónoma de México. Profesor de Carrera Titular "C" de Tiempo Completo Definitivo, adscrito en la Facultad de Estudios Superiores Iztacala de la Universidad Nacional Autónoma de México. Docente y Tutor en los programas de Doctorado en Psicología, 
Maestría y Doctorado en Ciencias Médicas Odontológicas y de la Salud, y Maestría en Enfermería, de la Universidad Nacional Autónoma de México. Dirección electrónica: josesapien@hotmail.com

Registro ORCID: https://orcid.org/0000-0001-8287-8383

Estefany Berenice Manjarrez Hernández

Maestra en Enfermería -Orientación en Educación- (con Mención Honorífica) por la Universidad Nacional Autónoma de México, Licenciada en Enfermería y Obstetricia por la Escuela Nacional de Enfermería y Obstetricia de la Universidad Nacional Autónoma de México. Actualmente desempeña el Rol Clínico en el Hospital Angeles Pedregal en la Unidad de Cuidados Intensivos. Docente en la Escuela de Enfermería del Instituto Nacional de Enfermedades Respiratorias y en la Universidad del Valle de México. Cursa el Diplomado "Atención de Enfermería en el Paciente Adulto en Estado Crítico". Desempeñó el rol docente y fungió como Coordinadora de Campos Clínicos.

Dirección electrónica: estefanyberenice2015@gmail.com

Registro ORCID: https://orcid.org/0000-0002-0592-2974 